\title{
Work-related ergonomic study among egg sellers- a study carried out West Garo Hills, Meghalaya
}

\author{
Ranima Saikia
}

Received: 04.08.2020; Revised: 20.10.2020; Accepted: 05.11.2020

Author for Correspondence :

\section{Ranima Saikia}

Department of Family Resource Management, Central

Agricultural University, Sangsanggre, West Garo Hills,

Tura (Meghalaya) India

Email : ranimasaikia@ rediffmail. com
ABSTRACT : The study has investigated the drudgery index and the musculoskeletal discomfort perceived by the respondents engaged in activities related to selling of eggs in the hilly terrain of West Garo Hills, Meghalaya. Findings reveal that cleaning of eggs is most drudgery prone compared to other activities they perform. The activity demands the use of small muscles and continuous movement of the hand at wrist level while holding and cleaning the eggs by using paper/cloth. The activity of cleaning also demands more attention to avoid loss, as egg shells are more fragile. Moreover, the sellers felt discomfort at the mid back, lower back and buttocks due to prolong sitting posture they adopt and due to twisting of the body to reach the items kept at the sides and back. Thus, designing of functional work station is the need for this group of sellers so as to reduce the drudgery level to eliminate musculoskeletal disorders.

KEY WORDS: Drudgery, Musculoskeletal discomfort, Body Map, Postures

- HOW TO CITE THIS PAPER : Saikia, Ranima (2020). Work-related ergonomic study among egg sellersa study carried out West Garo Hills, Meghalaya. Asian J. Home Sci., 15 (2) : 255-259, DOI: 10.15740/HAS/ AJHS/15.2/255-259. Copyright@ 2020: Hind Agri-Horticultural Society. 